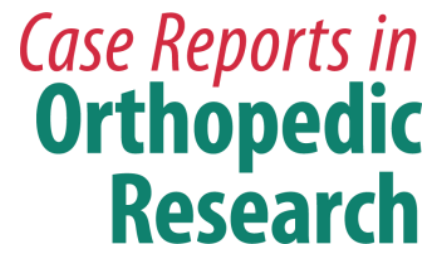

Case Rep Orthop Res 2019;2:14-20

DOI: 10.1159/000500235

Published online: May 8, 2019

C) 2019 The Author(s)

Published by S. Karger AG, Basel

www.karger.com/cio

This article is licensed under the Creative Commons Attribution-NonCommercial 4.0 International License (CC BY-NC) (http://www.karger.com/Services/OpenAccessLicense). Usage and distribution for commercial purposes requires written permission.

\title{
Femoral Neck Fracture in Idiopathic Hypercalciuria with Excessive Cola Consumption: A Case Report
}

\author{
Guoju Hong ${ }^{a, b}$ Xiaorui Han ${ }^{c}$ Wei He $e^{b, d}$ Felix Yao ${ }^{e}$ Jiake Xu ${ }^{e}$ \\ Leilei Chen ${ }^{c, d}$ \\ aDepartment of Surgery, University of Alberta, Edmonton, AB, Canada; 'baboratory of \\ Orthopedics of Chinese Medicine, Lingnan Medical Research Center, Guangzhou \\ University of Chinese Medicine, Guangzhou, PR China; 'Radiography Department, \\ Guangzhou First People's Hospital, the Second Affiliated Hospital of South China

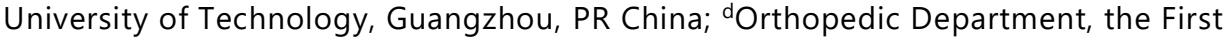 \\ Affiliated Hospital of Guangzhou University of Chinese Medicine, Guangzhou, PR China; \\ eSchool of Biomedical Sciences, The University of Western Australia, Perth, WA, Australia
}

\section{Keywords}

Hip · Osteoporosis · Trauma

\begin{abstract}
Idiopathic hypercalciuria is a metabolic defect characterized by excess renal calcium excretion, which can lead to bone mineral loss and an increased propensity to bony fractures. It is more commonly found among Caucasians and is present in the general population with a frequency of $5-10 \%$, but can reach $45-50 \%$ in subjects affected by nephrolithiasis. Here we report the case of a young 35-year-old male who developed primary osteoporosis secondary to idiopathic hypercalciuria and sustained a femoral neck fracture after a minor-impact fall. Laboratory findings revealed high urine calcium, low serum potassium, and high serum alkaline
\end{abstract}


phosphatase levels. Low-velocity traumatic bone injury was found in a young patient with hypercalciuria, which may indicate that bone status must be evaluated and followed up in these patients.

(C) 2019 The Author(s)

Published by S. Karger AG, Basel

\section{Introduction}

Hypercalciuria is the most common cause of calcium kidney stone disease. It can be "idiopathic" when clinical, laboratory, and radiographic investigations fail to delineate an underlying cause, or "secondary" when a known process produces excessive urinary calcium excretion (e.g., hyperparathyroidism, renal tubular acidosis, cancers, Paget's disease, Cushing syndrome) [1]. The pathogenesis of idiopathic hypercalciuria is unknown and could be secondary to increased intestinal absorption, reduced renal tubular reabsorption, increased osseous resorption, or a combination of these factors. It is a metabolic defect characterized by elevated urinary calcium excretion without concomitant serum hypercalcemia. Idiopathic hypercalciuria accounts for approximately $50 \%$ of calcium oxalate nephrolithiasis and is thought to contribute to stone formation by creating a urine supersaturated with calcium, oxalate, or phosphate. Therefore, associated symptoms may include abdominal pain, hematuria, dysuria, or urinary frequency. In addition, decreased bone mineral density and increased prevalence of bone fractures has been associated in patients with idiopathic hypercalciuria. Osteoporosis in affected young individuals is usually insidious and largely asymptomatic until sufficient bone matrix has been lost for fractures to occur. We report the case of a young patient with idiopathic hypercalciuria with concomitant diet and bone disorders to highlight the distinct clinical manifestations of this metabolic disorder.

\section{Case Report}

On April 11, 2014, a 35-year-old man was referred to the Emergency Department of the First Affiliated Hospital of Guangzhou University of Chinese Medicine, with severe right hip pain after a low-impact fall $9 \mathrm{~h}$ previously from a standing position. The patient had been in good health attributable to his young age, and usually did not take any regular medications. He is a nonsmoker, seldom drinks, but mentioned he was addicted to cola and reported a daily intake of approximately $3 \mathrm{~L}$ for the last 15 years. Physical examination revealed a shortened, rotated right lower limb with extensive bruising and swelling in the traumatic area. Hip and pelvic radiographs (Fig. 1) revealed a right femoral neck fracture (Garden III). CT examination (Fig. 2) demonstrated advanced osteopenia, and chest X-ray showed old bilateral rib fractures with unknown reason. T score of DEXA of this case is -3.3 indicating osteoporosis (a T score of -2.5 or below is a diagnosis of osteoporosis). There was a limited joint movement of the case. Ultrasound examination showed normal anatomy of the kidneys, thyroid and parathyroid glands. Biochemistry tests were conducted as follows (Table 1).

The patient was admitted for surgical internal fixation of the femoral neck fracture with free fibular transplantation. Serum levels of glucose and potassium were monitored and corrected during the inpatient management (Table 2). 


\section{Case Reports in Orthopedic Research}

\section{Results}

He was discharged with follow-up for regular monitoring of his renal function and bone mineral density, and education to adjust his dietary intake of cola in addition to long-term adherence to diets that feature normal levels of calcium, low protein and salt, and are high in fiber.

\section{Discussion/Conclusion}

Idiopathic hypercalciuria is a relatively common metabolic abnormality characterized by excessive urinary excretion of calcium (defined as $>250 \mathrm{mg} / 24 \mathrm{~h}$ for women and $>275-300$ $\mathrm{mg} / 24 \mathrm{~h}$ for male, $1 \mathrm{~mol}=40 \mathrm{mg}$ ) with relatively normal serum levels of calcium. The definite cause of the disorder is not clearly understood, with recent research implicating genetic, hormonal, and dietary factors. Idiopathic hypercalciuria should be identified against other secondary diseases with hypercalciuria, including primary hyperparathyroidism, renal tubular acidosis, Bartter syndrome, Paget's disease, and Cushing syndrome. Symptoms of idiopathic hypercalciuria are the result of altered calcium-phosphorus metabolism and/or kidney disorders, and may manifest clinically as lumbar pain, microscopic hematuria, obstructing stones, urinary tract infection, and osteoporosis [2]. Case reports of idiopathic hypercalciuria, especially with osteoporosis, are rare with the majority of reports originating from Europe. In 1975, Fanconi et al. [3] first reported a case of an 18-year-old boy with growth retardation and severe generalized osteoporosis associated with hypercalciuria. Tieder and Stark [4] reported siblings who were conceived from two closely related couples with a severe form of childhood idiopathic hypercalciuria associated with dwarfism, renal defects, and bony lesions. Pumarino [5] reported the case of a 61-year-old with severe osteopenia and osteoporosis secondary to a prolonged dietary restriction of calcium in the presence of high urinary calcium loss.

In this case report, we describe the presentation of a young man with severe osteoporosis associated with hypercalciuria and retrospectively reviewed the presenting features, and biochemical and radiographic findings. Primary hyperparathyroidism was excluded based upon normal levels of blood calcium and parathyroid hormone [6]. Other known causes of hypercalciuria such as sarcoidosis, Cushing syndrome, cancer, excessive vitamin D intake, hyperthyroidism, glucocorticoid use, Paget's disease, or renal tubular acidosis were absent. Potassium plays an important role in acid-base homeostasis and protects against bone resorption [7], and low levels were observed in this patient which correlates with chronic high urine calcium excretion and/or osteoporosis. Studies have demonstrated that increased consumption of cola beverages may increase the risk of osteoporosis and fragility fracture, although the physiological mechanisms are not completely understood [8, 9]. Reports suggest that the increased phosphoric acid content in these beverages alter the balance of serum calcium, phosphate, parathyroid hormone, and osteocalcin which negatively affects bone health $[9,10]$. In addition, caffeine consumption is a known risk factor for osteoporosis due to its propensity to alter urinary excretion of calcium posing a risk for hypercalciuria [11]. This case report presents a young man who suffered a hip fracture following a low-impact injury with associated 


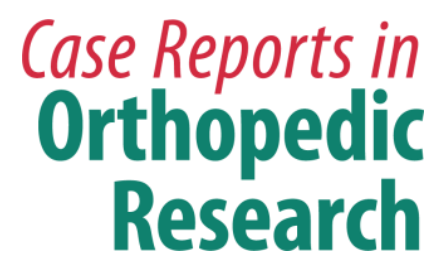

Case Rep Orthop Res 2019;2:14-20

hypercalciuria. This is important since high cola and caffeine consumption are known risk factors for osteoporosis.

\section{Acknowledgement}

Guoju Hong and Jiake Xu made mutual collaborative visits in 2015 to 2016.

\section{Statement of Ethics}

The authors have no ethical conflicts to disclose. The authors have informed the subject about the publication of this case before submitting the report and the subject gave written informed consent. This case report was approved by the clinical ethic commission of the First Affiliated Hospital of Guangzhou University of Chinese Medicine (No. ZYYECK[2015]005).

\section{Disclosure Statement}

The authors have no conflicts of interest to declare.

\section{Funding Sources}

This case report was funded by: National Nature Science Foundation of China (grant No. 81673999) and Guangdong Natural Science Funds for Distinguished Young Scholars (grant No. 2015A030306037).

\section{Author Contributions}

Guoju Hong involved the case and supervised the study; Wei He and Leilei Chen performed the surgery; Xiaorui Han analyzed data; Guoju Hong wrote the manuscript; Felix Yao and Jiake Xu made manuscript revisions.

\section{References}

1 Cioppi F, Taddei L, Brandi ML, Croppi E. Idiopathic hypercalciuria and calcium renal stone disease: our cases. Clin Cases Miner Bone Metab. 2009 Sep;6(3):251-3.

2 Asplin JR, Bauer KA, Kinder J, Müller G, Coe BJ, Parks JH, et al. Bone mineral density and urine calcium excretion among subjects with and without nephrolithiasis. Kidney Int. 2003 Feb;63(2):662-9.

3 Fanconi A, Fanconi G. Uncommon form of idiopathic osteoporosis with hypercalciuria, growth retardation and mental retardation. Helv Paediatr Acta. 1975 May;30(1):79-88.

4 Tieder M, Stark H. [Familial form of idiopathic hypercalciuria with nanism, bone and renal involvement in children]. Helv Paediatr Acta. 1979 Sep;34(4):359-67. 


\section{Case Reports in Orthopedic Research}

Hong et al.: Femoral Neck Fracture in Idiopathic Hypercalciuria

5 Pumarino H. [Osteoporosis in a man with idiopathic hypercalciuria, renal variety, treated with a hypocalcic diet]. Rev Med Chil. 1990 Apr;118(4):437-40.

6 Brixen KT, Christensen PM, Ejersted C, Langdahl BL. Teriparatide (biosynthetic human parathyroid hormone 1-34): a new paradigm in the treatment of osteoporosis. Basic Clin Pharmacol Toxicol. 2004 Jun;94(6): $260-70$.

7 Coe FL, Parks JH. Idiopathic hypercalciuria: the contribution of Dr. Jacob Lemann, Jr. J Am Soc Nephrol. 1994 Nov;5(5 Suppl 1):S59-69.

8 Baylink DJ. The diagnosis and management of osteoporosis. Z Rheumatol. 2000;59 Suppl 1:42-4.

9 Kristensen M, Jensen M, Kudsk J, Henriksen M, Mølgaard C. Short-term effects on bone turnover of replacing milk with cola beverages: a 10-day interventional study in young men. Osteoporos Int. 2005 Dec;16(12):1803-8.

10 Calvo MS, Tucker KL. Is phosphorus intake that exceeds dietary requirements a risk factor in bone health? Ann N Y Acad Sci. 2013 Oct;1301(1):29-35.

11 Massey LK, Whiting SJ. Caffeine, urinary calcium, calcium metabolism and bone. J Nutr. 1993 Sep;123(9):1611-4.

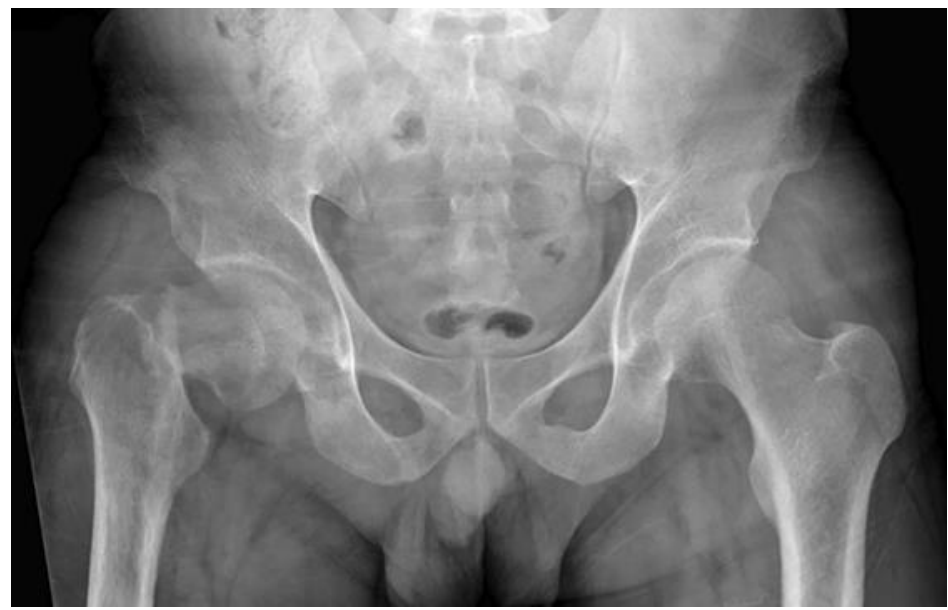

Fig. 1. Right femoral neck fracture (Emergency Department). A pelvic radiograph shows right femoral neck fracture that belongs to $\mathrm{C}$ type according to the Garden classification. 


\section{Case Reports in Orthopedic Research}

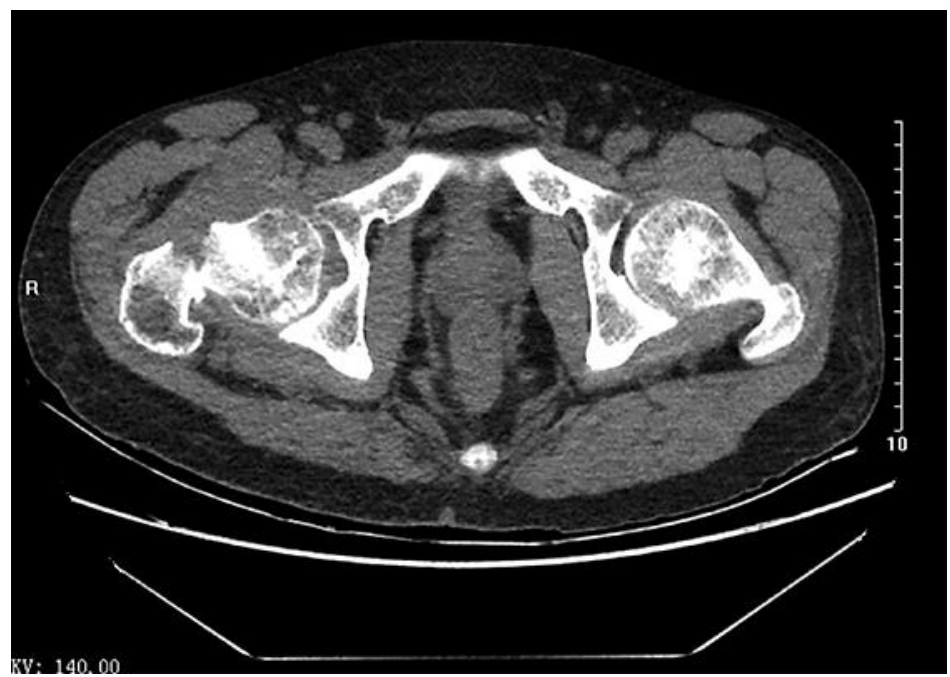

Fig. 2. Osteoporosis and femoral neck fracture. CT scan suggesting that bilateral bone mineral density indicates osteopenia.

Table 1. Biochemical test investigated at first detection in the Emergency Department

\begin{tabular}{llll}
\hline Items & Score & Regulated & Normal range \\
\hline White blood cell count & $20.65 \times 109 / \mathrm{L}$ & High & $4-10 \times 10^{9} / \mathrm{L}$ \\
Neutrophil percentage & $78.9 \%$ & High & $50.0-70.0 \%$ \\
C-reactive protein & $28.5 \mathrm{mg} / \mathrm{L}$ & High & $\leq 10 \mathrm{mg} / \mathrm{L}$ \\
Serum K & $3.02 \mathrm{mmol} / \mathrm{L}$ & Low & $3.5-5.5 \mathrm{mmol} / \mathrm{L}$ \\
Blood glucose & $8.31 \mathrm{mmol} / \mathrm{L}$ & High & $3.89-6.11 \mathrm{mmol} / \mathrm{L}$ \\
Urine occult blood & $1+$ & High & - \\
Alkaline phosphatase & $686 \mathrm{U} / \mathrm{L}$ & High & $45-125 \mathrm{U} / \mathrm{L}$ \\
Plasma phosphorus & $0.72 \mathrm{mmol} / \mathrm{L}$ & Low & $0.90-1.34 \mathrm{mmol} / \mathrm{L}$ \\
Urinary Ca2+ & $9.93 \mathrm{mmol} / 24 \mathrm{~h}$ & High & $2.7-7.5 \mathrm{mmol} / 24 \mathrm{~h}$ \\
Serum Ca ${ }^{+}$ & $2.46 \mathrm{mmol} / \mathrm{L}$ & Normal & $2.25-2.75 \mathrm{mmol} / \mathrm{L}$ \\
Serum creatinine & $87 \mu \mathrm{moI} / \mathrm{L}$ & Normal & $54-106 \mu \mathrm{moI} / \mathrm{L}$ \\
Procollagen type I N-terminal propeptide & $353.2 \mathrm{ng} / \mathrm{mL}$ & High & $0.016-0.055 \mathrm{ng} / \mathrm{mL}$ \\
$\beta$-C-terminal telopeptide of type I collagen & $1.70 \mathrm{ng} / \mathrm{mL}$ & High & $0.1-0.65 \mathrm{ng} / \mathrm{mL}$ \\
N-MID osteocalcin & $48.40 \mathrm{ng} / \mathrm{mL}$ & High & $10-23 \mathrm{ng} / \mathrm{mL}$ \\
25-hydroxy-vitamin D & $55.22 \mathrm{nmol} / \mathrm{mL}$ & High & $8.0-30.5 \mathrm{ng} / \mathrm{mL}$ \\
Total protein & $56.0 \mathrm{~g} / \mathrm{L}$ & Low & $65-85 \mathrm{~g} / \mathrm{L}$ \\
Albumin & $39.3 \mathrm{~g} / \mathrm{L}$ & Low & $40-55 \mathrm{~g} / \mathrm{L}$ \\
$\gamma$-Globulin & $16.7 \mathrm{~g} / \mathrm{L}$ & Low & $20-40 \mathrm{~g} / \mathrm{L}$ \\
Albumin/ $\gamma$-globulin & 2.4 & Low & $1.5-2.5$ \\
\hline
\end{tabular}


Case Reports in Orthopedic Research

Hong et al.: Femoral Neck Fracture in Idiopathic Hypercalciuria

Table 2. Dynamic levels of blood glucose and serum potassium during the perioperative period

\begin{tabular}{lllllllll}
\hline Item & \multicolumn{2}{l}{ Dynamic level } & & & & \\
\cline { 2 - 8 } & April 12 & April 13 & April 14 & April 16 & April 17 & April 18 & April 23 & normal range \\
\hline Blood glucose, mmol/L & 8.31 & 8.37 & 8.98 & 10.43 & 14.57 & 7.31 & 7.31 & $3.89-6.11$ \\
Serum K+, mmol/L & 3.02 & 2.87 & 2.69 & 3.67 & 3.96 & 4.34 & 3.57 & $3.5-5.5$ \\
\hline
\end{tabular}

